\section{Morrison dental chair}

By Rachel Bairsto, Head of Museum Services, British Dental Association Museum

The first dental chair to have any form of movement was designed by James Snell in 1831. It allowed some adjustment to the seat and back. Further improvements to dental chairs were vital, as Claudius Ash [an English goldsmith and dental manufacturer] made clear: 'Properly designed, it is conducive to quick and accurate working, agreeable to both patient and operator and if the design be also in a true and artistic spirit, there is introduced a psychological factor of real value. Most people are susceptible to the tranquillising influence of the beautiful and refined'.

James Beall Morrison (1829-1917), a dentist from St. Louis, Missouri, seems to have taken all this into account in the design of this chair (pictured). He spent time practising in Paris and London and it is likely that he developed this design whilst in London, as he received a British patent on 7 December 1867. In line with other dental chairs, he moved away from wood and chose cast iron for the framework. His first chair had a triangular base on which the chair could tilt in all directions on a ball and socket, but a second patent issued in America upon his return there the following year shows this was substituted by four legs.

Morrison's was the first chair to introduce the compensating backrest, the lower portion of which could be moved forward to support the small of the patient's back and the upper part of which could be lowered or raised. The chair back was also narrower than its predecessors to stop the dentist stretching so much. The arms could also be dropped out of the way to allow the operator greater access. Patients could make themselves more comfortable by selfadjusting the footrest without disturbing the operator. The headrest could be slid backwards and forwards and completely removed for working on small children.

In its day this chair had the greatest vertical range then achieved. It took seven seconds to be moved from 15 inches high to 42 inches.

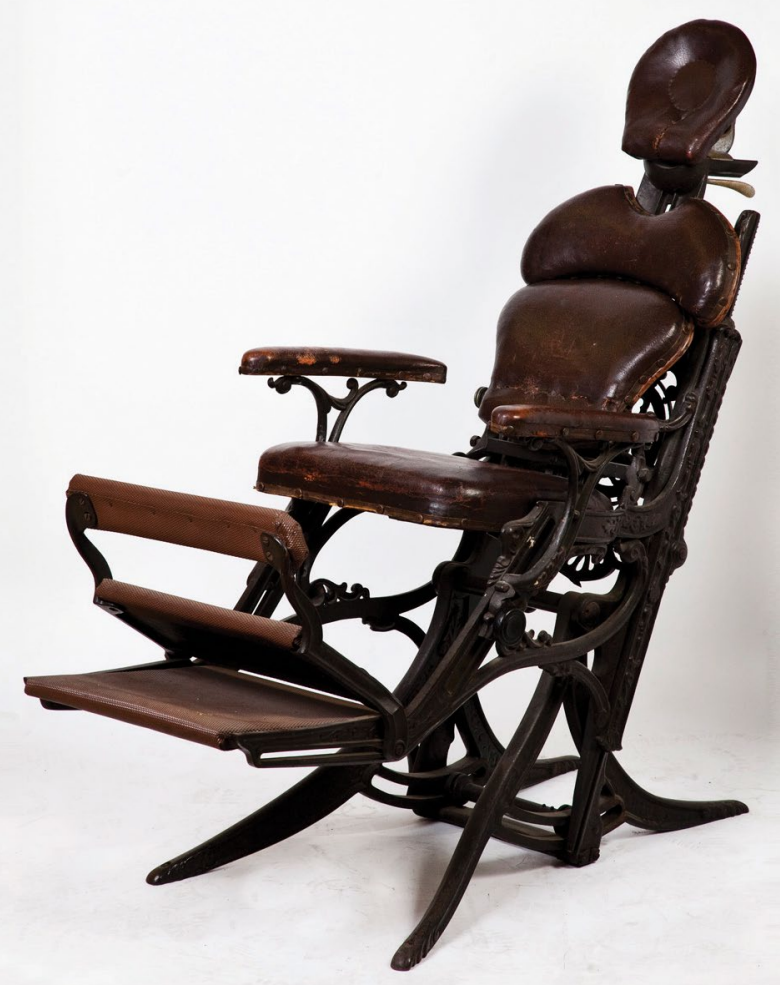

Because of these innovations, the Morrison chair was the first chair to allow the dentist to work from a sitting or standing position, although most dentists continued with the latter for nearly a century.

The ornate ironwork was complemented by the brown rexine finish, a type of imitation leather with a cheaper cord finish for dental students. Fringed Turkish upholstery, described as 'soft and with springs', was another option and seats made of cane could be inserted by the operator for summer use.

Morrison went on to design the first commercially manufactured foot drill; however, it was the royalties from half a century's worth of sales of his chair that were the foundation of his wealth.

\title{
Dental Surgeon - preserved and revitalised!
}

A copy of Dental Surgeon from 1917 has been rebound thanks to money raised by the British Dental Association's (BDA's) Library Historical Preservation Fund.

Helen Nield, Head of Library and Knowledge Services at the BDA, said: 'Thank you to everybody that donated to our BDA Library fund to preserve and rebind this important historical journal. On my weekly visit to the Library, I was able to receive the refreshed volume from the binders'.

If you wish to contribute to the Library Historical Preservation Fund to aid in rebinding some of our more dilapidated volumes of the $B D J$ and other dental works visit http://uk.virginmoneygiving. com/fund/BDALibraryHPF.
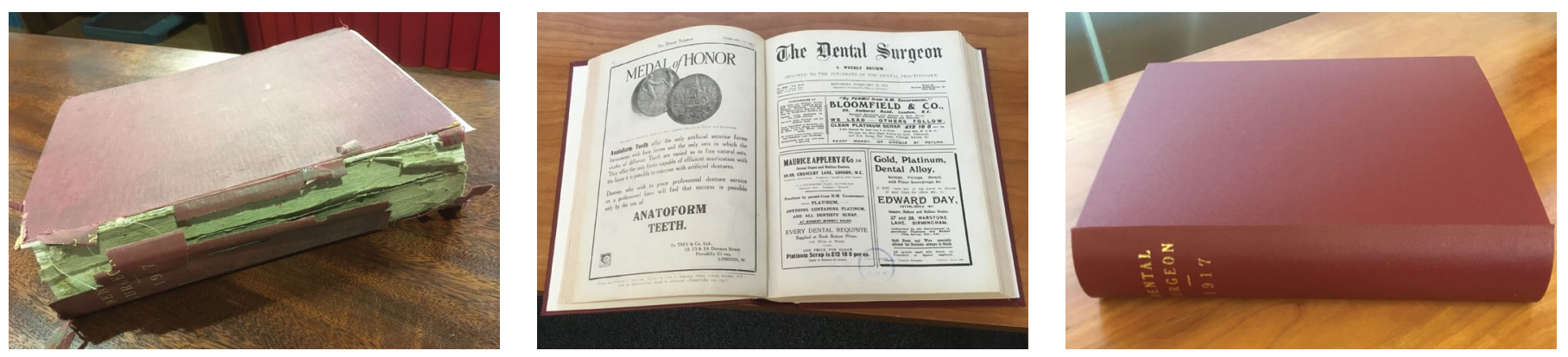